Letters

\section{Self-diagnosed COVID-19 in people with multiple sclerosis: a community-based cohort of the UK MS Register}

\section{INTRODUCTION}

In the early phases of the UK COVID-19 outbreak, in the absence of clear evidence about the risks for people with multiple sclerosis (pwMS) and those taking immunomodulatory disease-modifying therapies (DMT), we launched a community-based study as part of the UK MS Register (UKMSR). We intended to capture the picture of COVID-19 among pwMS and their risk of contracting the disease. Here, we report our findings from 17 March to 24 April 2020.

\section{METHODS}

The COVID-19 study (clinicaltrials.gov: NCT04354519) is a prospective observational cohort launched on 17 March 2020 as part of the UKMSR (Ethics:16/ SW/0194). PwMS completed a specific COVID-19 related survey which was combined with data held from before the pandemic where available. The primary outcome of the study is participantreported self-diagnosis of COVID-19. Participants were asked if their diagnosis was confirmed by testing-the available test in the UK was reverse
transcriptase-PCR. Participants reported if their sibling without MS, closest in age who was not living with them, had selfdiagnosed COVID-19. The likelihood of having COVID-19 was assessed using multivariable regression analysis with the variables: age, gender, ethnicity, MS duration and type, self-isolation and DMTs. DMTs were considered after stratifying based on moderate-efficacy versus highefficacy therapies (table 1). Disability was assessed using the last recorded web-based Expanded Disability Status Scale (webEDSS) or MS Impact Scale v2 (MSIS-29v2).

\section{RESULTS}

As of 24 April, out of 3910 participants, $237(6.1 \%$ (95\% CI $5.3 \%$ to $6.8 \%))$ reported self-diagnosed COVID-19 among whom 54 (22.8\% (17.5\% to $28.2 \%)$ ) also had a diagnosis by a healthcare professional based on symptoms and 37 (15.6\% $(11.2 \%$ to $20.6 \%)$ ) a confirmed diagnosis by testing. Three participants reported hospitalisation due to COVID-19. No deaths were reported.

Among 1283 siblings without MS, $79(6.2 \%)$ had a reported diagnosis of COVID-19. Adjusting for age and gender, the likelihood of contracting COVID-19 in pwMS was similar to siblings (OR $1.180(0.888$ to 1.569$))$.

Seven hundred and fifty-nine of 3812 participants reported that they were self-isolating and that they had been self-isolating for at least 2 weeks before symptom onset if they had COVID-19. Of these, $2(0.3 \%(0 \%$ to $0.7 \%))$ had self-diagnosed COVID-19 whereas 137 of 3053 participants not self-isolating $(4.5 \%(3.8 \%$ to $5.2 \%))$ had the disease $(\mathrm{p}<0.001)$. Among participants with confirmed COVID-19, 94.6\% (86.5\% to $100 \%)$ were not self-isolating which was higher than those without the disease (79.9\% (78.7\% to $81.3 \%), p=0.023)$. Selfisolating participants were slightly older than those not self-isolating $(p<0.001)$. A lower proportion of participants on DMTs were self-isolating compared with those not taking DMTs (18.1\% (16.4\% to $20 \%)$ vs $21.5 \%(19.6 \%$ to $23.3 \%), p=0.01)$. Rate of self-isolation in participants taking high-efficacy DMTs was similar to those not taking DMTs and higher than those taking moderate-efficacy DMTs (21.3\% vs $21.4 \%$ and $16.5 \%, p=0.993$ and $\mathrm{p}=0.014$, respectively). More participants with progressive MS (PMS) were self-isolating compared with relapsingremitting MS (RRMS) (23.2\% (21\% to $25.3 \%)$ vs $17.9 \%$ (16.3\% to $19.5 \%)$, $\mathrm{p}<0.001)$.

Using self-diagnosed and confirmed COVID-19 as outcomes, 3714 and 3618 participants were included in the regression analysis, respectively. Self-isolation predicted a lower likelihood of having selfdiagnosed COVID-19 (OR 0.064 (0.016 to 0.259$)$ ) but not confirmed COVID-19.

Participants on DMTs were less likely to have self-diagnosed COVID-19 (OR 0.640 (CI 0.428 to 0.957$)$ ), which remained significant after removing

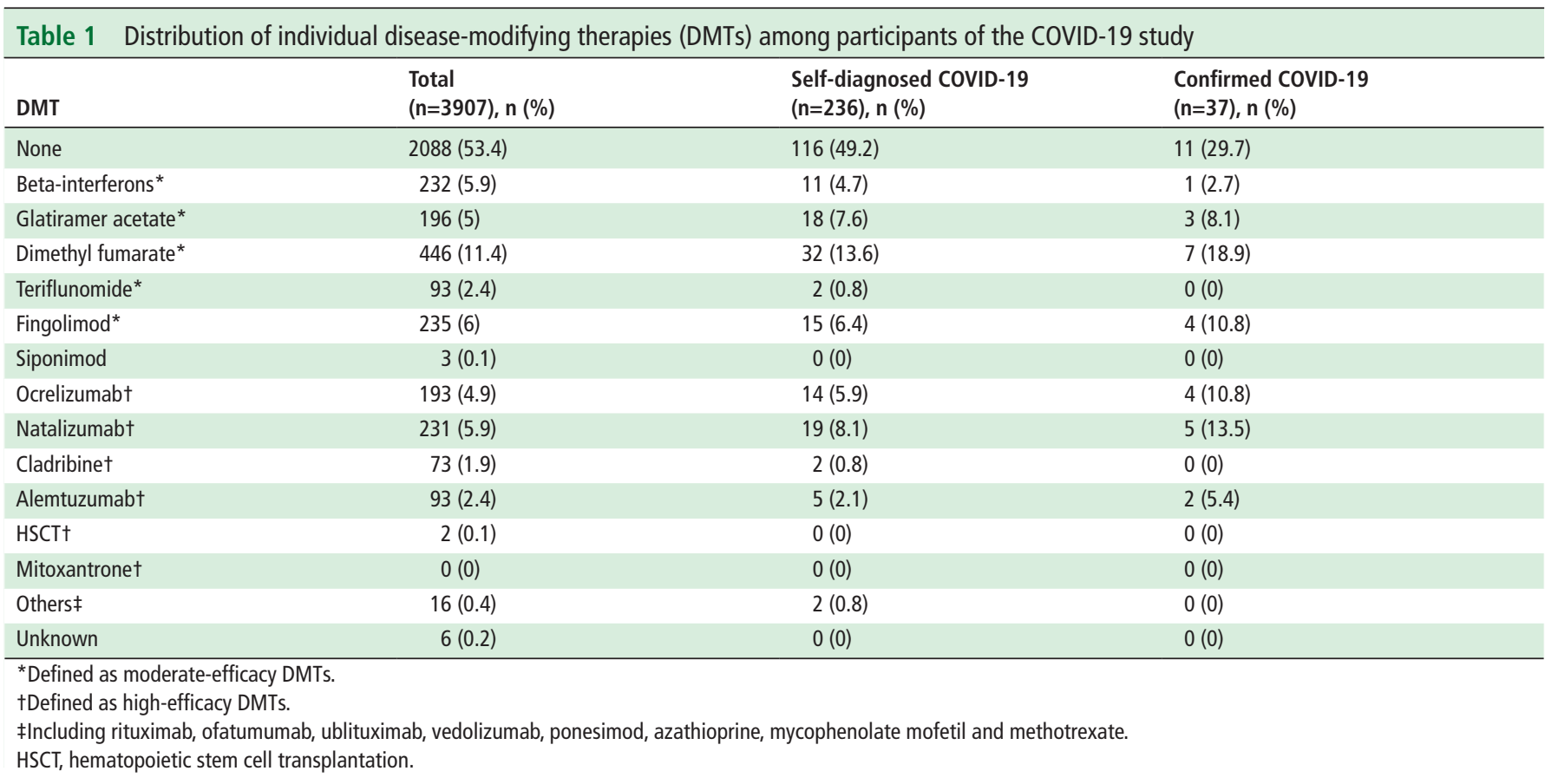


self-isolating participants (OR 0.633 $(0.402$ to 0.998$))$. High-efficacy DMTs reduced the likelihood of self-diagnosed COVID-19 compared with no DMTs (OR $0.540(0.311$ to 0.938$)$ ) but not compared with moderate-efficacy DMTs. There was no significant association between taking DMTs and having confirmed COVID-19. It was not possible to do a formal statistical test for the association between individual DMTs and COVID-19 due to small numbers (table 1).

Younger age was associated with increased likelihood of having selfdiagnosed (OR 1.043 (1.022 to 1.064)) and confirmed (OR $1.048 \quad(1.009$ to 1.087)) COVID-19.

Participants with PMS were less likely to have self-diagnosed (OR 0.429 (0.241 to 0.763$)$ ) or confirmed (OR $0.119(0.015$ to 0.967$)$ ) COVID-19 compared with those with RRMS, but this effect disappeared after excluding participants who were self-isolating.

Including webEDSS $(\mathrm{n}=2808)$ and physical MSIS-29v2 $(n=3192)$ as additional predictors in the analysis showed no significant association with the likelihood of contracting COVID-19.

The gender distribution was similar between participants with and without COVID-19. More participants with selfdiagnosed COVID-19 reported themselves as having any ethnicity other than white compared with those without the disease $(6.9 \%$ (3.9\% to $10.1 \%)$ vs $3.8 \%$ (3.2\% to $4.4 \%), p=0.019)$. Gender and ethnicity did not affect the likelihood of having COVID-19.

\section{DISCUSSION}

We report initial findings of an ongoing community-based COVID-19 study in a large UK-wide population of pwMS which coincided with the peak of the COVID-19 outbreak in the UK. ${ }^{1}$ We show that pwMS taking immunomodulatory treatments do not have an increased risk of contracting COVID19. We did not find individual DMTs to be noticeably over-represented among pwMS with COVID-19.

The incidence of COVID-19 in our population of pwMS was not higher than that of the general population, ${ }^{2}$ and pwMS were not at a higher risk of having COVID-19 compared with their siblings without MS. The low hospitalisation rate in our population is possibly due to its patient-reported nature where hospitalised pwMS would fail to respond to the surveys.
The observation that self-isolating pwMS had a lower risk of COVID-19 was not unexpected. We found older pwMS and those with PMS were less likely to have COVID-19. This could be because they were self-isolating more. Similar to previous reports, we found evidence that pwMS with any ethnicity other than white had a higher chance of contracting COVID-19, ${ }^{3}$ but larger numbers are required to confirm this.

When this study launched, there was no accurate or accessible test to diagnose COVID-19. Therefore, we decided to set a diagnosis of COVID-19 made by participants, based on their symptoms, as the primary outcome of the study. This approach has also been adopted in other large-scale studies and is in line with the UK government policy not to seek medical advice for mild symptoms of COVID$19 .^{45}$

In conclusion, during a period with strict precautions in place to prevent the spread of COVID-19, pwMS and those taking DMTs are not at an increased risk of contracting the disease.

Nikos Evangelou, ${ }^{1}$ Afagh Garjani $\odot{ }^{2}$

Roshan dasNair, ${ }^{3}$ Rachael Hunter, ${ }^{4}$

Katherine A Tuite-Dalton, ${ }^{5}$ Elaine M Craig, ${ }^{5}$

William J Rodgers, ${ }^{5}$ Alasdair Coles, ${ }^{6}$

Ruth Dobson $\odot{ }^{7}{ }^{7}$ Martin Duddy, ${ }^{8}$

David Vincent Ford ${ }^{5}$ Stella Hughes, ${ }^{9}$

Owen Pearson, ${ }^{10}$ Linda A Middleton, ${ }^{11}$

David Rog, ${ }^{12}$ Emma Clare Tallantyre $\odot$, 13,14

Tim Friede, ${ }^{15}$ Rodden M Middleton, ${ }^{5}$

Richard Nicholas ${ }^{16,17}$

${ }^{1}$ Division of Clinical Neuroscience, University of Nottingham, Nottingham, UK

${ }^{2}$ Department of Neurology, Nottingham University

Hospitals NHS Trust, Nottingham, UK

${ }^{3}$ Division of Psychiatry and Applied Psychology,

University of Nottingham, Nottingham, UK

${ }^{4}$ College of Human and Health Sciences, Swansea

University, Swansea, UK

${ }^{5}$ Population Data Science, Swansea University Medical School, Swansea, UK

${ }^{6}$ Department of Clinical Neurosciences, University of Cambridge, Cambridge, UK

${ }^{7}$ Blizard Institute, Queen Mary University London, London, UK

${ }^{8}$ Neurosciences, Newcastle Upon Tyne Hospitals NHS Foundation Trust, Newcastle Upon Tyne, UK

${ }^{9}$ Neurology, Belfast Health and Social Care Trust, Belfast, UK

${ }^{10}$ Department of Neurology, Swansea Bay University Health Board, Port Talbot, UK

${ }^{11}$ Ed Major Intensive Care Unit, Swansea Bay University Health Board, Port Talbot, UK

${ }^{12}$ Department of Neurology, Greater Manchester Neurosciences Centre, Salford Royal NHS Foundation Trust, Salford, UK

${ }^{13}$ Helen Durham Centre for Neuroinflammatory Disease, University Hospital of Wales, Cardiff, UK

${ }^{14}$ Institute for Psychological Medicine and Clinical Neuroscience, Cardiff University, Cardiff, UK

${ }^{15}$ Medical Statistics, University Medical Center Göttingen, Göttingen, Germany

${ }^{16}$ Department of Translational Neuroscience, Imperial College London Faculty of Medicine, London, UK
${ }^{17}$ Department of Visual Neuroscience, University College London, London, UK

Correspondence to Dr Richard Nicholas, Neurology, Imperial College London Faculty of Medicine, London, London, UK; r.nicholas@imperial.ac.uk

Twitter Ruth Dobson @drruthdobson

Contributors NE, AG, RN and RMM made a substantial contribution to the work. AG, WJR, TF, EMC, KAT-D and DVF acquired, analysed and interpreted data. $A C, R d, R H, S H, O P, D R, E C T$ and $M D$ revised it critically for important intellectual content.

Funding This study was funded by Multiple Sclerosis Society (http://dx.doi.org/10.13039/501100000381) and grant number: MSREG-001.

Competing interests RMM, WJR, EC, KAT-D, DVF and $A G$ as part of the UK MS Register have received grants from the MS Society. DR reports consulting fees from Bayer, Biogen, MedDay, Merck Serono, Novartis, Roche, Sanofi Genzyme and Teva Neuroscience and research support from Actelion, Biogen, GW Pharma, MedDay, Merck Serono, Mitsubishi, Novartis, Sanofi Genzyme, Teva Neuroscience and TG Therapeutics. ECT has received consulting or speaker fees from Roche, Novartis and Takeda and travel expenses to attend educational meetings from Biogen, Merck, Roche. AC has received honoraria and travel expenses from Sanofi, up until September 2017. OP has received honoraria and travel expenses from Biogen, Bayer, Genzyme, Merck, Novartis, Roche and Teva and served on advisory boards for Biogen, Celgene, Novartis, Genzyme, Merck and Roche. SH has received an unrestricted educational grant from Merck Serono and travel grants from Biogen Idec, Novartis and Sanofi-Aventis. MD has received speaker honoraria, consulting fees and travel grants from Bayer, Biogen Idec, Novartis UK, Merck Serono, Roche and Teva UK over the past 5 years. RD has received speaker honoraria from Biogen Idec, Teva, Neurology Academy, Sanofi Genzyme and research support from Biogen, Merck, Celgene. NE is a member of the advisory board for Biogen, Merck, Novartis and Roche and receives grant income from MS Society, MRC, PCORI and NIHR. RdN reports membership of the NIHR Health Services \& Delivery Research committee and is the Chair of the NIHR Research for Patient Benefit East Midlands Research Advisory Committee. He has received funding to prepare and deliver lectures on cognitive rehabilitation in multiple sclerosis from Novartis and Biogen. TF reports personal fees from Novartis, personal fees from Bayer, personal fees from AstraZeneca, personal fees from Janssen, personal fees from Roche, personal fees from Mediconomics, personal fees from Boehringer Ingelheim, personal fees from Daiichi-Sankyo, personal fees from Galapagos, personal fees from Penumbra, personal fees from Parexel, personal fees from CSL Behring, personal fees from Fresenius Kabi, personal fees from Biosense Webster, personal fees from Enanta, personal fees from IQVIA. RN reports support from advisory boards and travel expenses from Novartis, Roche and Biogen. He has grant support from the UK MS Society and is a member of a NICE HTA committee.

Patient consent for publication Not required.

Provenance and peer review Not commissioned; externally peer reviewed.

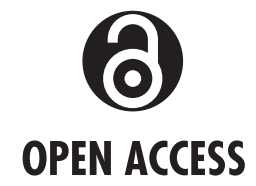

Open access This is an open access article distributed in accordance with the Creative Commons Attribution Non Commercial (CC BY-NC 4.0) license, which permits others to distribute, remix, adapt, build upon this work 
non-commercially, and license their derivative works on different terms, provided the original work is properly cited, appropriate credit is given, any changes made indicated, and the use is non-commercial. See: http:// creativecommons.org/licenses/by-nc/4.0/.

(C) Author(s) (or their employer(s)) 2021. Re-use permitted under CC BY-NC. No commercial re-use. See rights and permissions. Published by BMJ.

\section{D) Check for updates}

To cite Evangelou N, Garjani A, dasNair R, et al. J Neurol Neurosurg Psychiatry 2021;92:107-109.

Received 30 June 2020

Revised 25 July 2020

Accepted 5 August 2020

Published Online First 27 August 2020

J Neurol Neurosurg Psychiatry 2021;92:107-109. doi:10.1136/jnnp-2020-324449

\section{ORCID iDs}

Afagh Garjani http://orcid.org/0000-0001-9271-346X

Ruth Dobson http://orcid.org/0000-0002-2993-585X

Emma Clare Tallantyre http://orcid.org/0000-0002-

3760-6634

Richard Nicholas http://orcid.org/0000-0003-0414-

1225

\section{REFERENCES}

1 UK Government. Coronavirus (COVID-19) in the UK. Available: https://coronavirus.data.gov.uk/ [Accessed July 2020].

2 Drew DA, Nguyen LH, Steves CJ, et al. Rapid implementation of mobile technology for real-time epidemiology of COVID-19. Science 2020;368:1362-7.

3 Kirby T. Evidence mounts on the disproportionate effect of COVID-19 on ethnic minorities. Lancet Respir Med 2020;8:547-8.

4 Menni C, Valdes AM, Freidin MB, et al. Real-Time tracking of self-reported symptoms to predict potential COVID-19. Nat Med 2020:1-4.

5 UK Government. Guidance for households with possible coronavirus (COVID-19) infection. Available: https:// www.gov.uk/government/publications/covid-19-stay-athome-guidance/stay-at-home-guidance-for-householdswith-possible-coronavirus-covid-19-infection [Accessed July 2020]. 